\title{
Assessment of Toxigenic Fusarium Species and Their Mycotoxins in Brewing Barley Grains
}

\author{
Karim C. Piacentini ${ }^{1, *}$, Liliana O. Rocha ${ }^{2}$, Geovana D. Savi ${ }^{3}{ }^{(1)}$, Lorena Carnielli-Queiroz ${ }^{4}$, \\ Livia De Carvalho Fontes ${ }^{4}$ and Benedito Correa ${ }^{1,4}$ \\ 1 Biotechnology Department, University of Sao Paulo, Av. Professor Lineu Prestes, Sao Paulo 2415, Brazil; \\ correabe@usp.br \\ 2 Department of Food Science, Food Engineering Faculty, University of Campinas, Av. Monteiro Lobato, 80, \\ Campinas 13083862, Brazil; 1.rocha@unicamp.br \\ 3 Department of Materials Sciences and Engineering, University of the Extreme Southern Santa Catarina, \\ Av. Universitaria, 1105 Criciuma, Santa Catarina 88807-400, Brazil; geovanasavi@gmail.com \\ 4 Microbiology Department, University of Sao Paulo, Av. Professor Lineu Prestes, Sao Paulo 1374, Brazil; \\ carnielli@usp.br (L.C.-Q.); livia.fontes@usp.br (L.D.C.F.) \\ * Correspondence: karim.piacentini@hotmail.com
}

Received: 14 November 2018; Accepted: 29 December 2018; Published: 10 January 2019

\begin{abstract}
Fusarium species threaten yield and quality of cereals worldwide due to their ability to produce mycotoxins and cause plant diseases. Trichothecenes and zearalenone are the most economically significant mycotoxins and are of particular concern in barley, maize and wheat. For this reason, the aim of this study was to characterize the Fusarium isolates from brewing barley and to assess deoxynivalenol and zearalenone contamination in grains. Characterization of the Fusarium strains was carried out by the phylogeny based on two loci (EF-1 $\alpha$ and RPB2). Mycotoxin detection and quantification were performed by LC-MS. The results show that Fusarium was the predominant genus. Phylogenetic study demonstrated that the majority of the strains clustered within the Fusarium sambucinum species complex followed by the Fusarium tricinctum species complex. The results revealed high incidence of deoxynivalenol (DON) and zearalenone (ZEA) contamination ( $90.6 \%$ and $87.5 \%$, respectively). It was observed that $86 \%$ of the samples contaminated with ZEA were above the limits set by the EU and Brazilian regulations. These results may highlight the importance of controlling Fusarium toxins in barley, mainly because of its use in the brewing industry and the resistance of various mycotoxins to food processing treatments.
\end{abstract}

Keywords: cereals; mycotoxigenic fungi; phylogeny; deoxynivalenol; zearalenone

Key Contribution: High contamination of deoxynivalenol and zearalenone was found in barley analyzed. Most of the samples contaminated were above to the limits set by the regulations.

\section{Introduction}

The Fusarium genus includes plant pathogens which are of great concern to agricultural production and food/feed safety worldwide [1], threatening yield and quality of cereals and producing mycotoxins, secondary metabolites that are toxic to humans and other animals [2]. Fusarium genus is capable of producing several mycotoxins, including fumonisins, trichothecenes and zearalenone. These are the most economically significant Fusarium mycotoxins and are of particular concern in barley, maize and wheat [3].

Trichothecenes have been classified into four groups: types A-D, according to their chemical structure [4], the most important in cereals are types A and B [1]. The B-trichothecenes include 
the mycotoxins deoxynivalenol (DON), its acetylated derivatives, 3-acetyldeoxynivalenol (3ADON) and 15-acetyldeoxynivalenol (15ADON) and nivalenol (NIV). DON is the most frequent type-B trichothecene and can be found worldwide. Furthermore, DON inhibits protein synthesis and it has been associated with intoxication of animals through consumption of contaminated feed [5].

Zearalenone (ZEA) is a mycotoxin with estrogenic effects produced by several Fusarium species and is usually found in cereal grains. Swine are especially sensitive to the estrogenic effects of ZEA. This toxin has been shown to bind to the estrogenic receptors and to inhibit ovulation. It is, therefore, often involved in hormonal disorders of farm animals and it is also related to hypoestrogenic syndromes in humans [6]. ZEA has been classified into group 3 (non-classifiable due to its carcinogenicity to humans) by IARC (International Agency for Research on Cancer) [7].

During recent years, mycotoxins have attracted international attention not only for their perceived impact on human health but also because of the economic losses accruing from contaminated foods. Considering barley matrix, several international studies have reported on Fusarium and its mycotoxins contamination due to the beer gaining increased popularity [8]. The main problem is the characteristics that these compounds have. Some mycotoxins such as trichothecenes, zearalenone and fumonisins are considered stable during the brewing process [9] and can persist to the final product, the beer. Furthermore, Fusarium infection causes a negative impact on barley germination rates which results in malting quality and yield reduction. Additionally, this produces gushing and changes in color and flavor of the beer [10].

Barley is considered to have good characteristics for fungi contamination under favorable conditions. In addition, environmental factors associated with barley varieties and agronomic practices influence the Fusarium infection and the mycotoxin production. The climate conditions during critical phases of barley plant growth could lead to noticeable difference between the mycotoxin diversity. Tropical conditions, such as those found in Brazil contribute to fungi dissemination and consequently mycotoxin production in barley. For example, 2015 demonstrated a high rainfall average and high levels of humidity, which prompted worse contamination levels found until now [11]. It is necessary to mention that only two Fusarium mycotoxins were analyzed. Other fungi mycotoxins should be evaluated along with their masked toxins.

All of the barley harvested in Brazil is destined for the brewing industry and the production continues to increase. Southern Brazil has the largest number of barley-producing regions, therefore, the quality of the grains needs to be monitored and studies about the fungi profile should be taken into account. The knowledge of the current contamination of barley in the region, as well as the constant monitoring, is necessary in order to evaluate if agronomic practices are being duly effective to control the contamination in grain production. The irrigation management, resistant cultivars, harvesting strategies, chemical and biological control and disease forecasting could minimize the loss of grain quality and avoid the disease caused by mycotoxigenic fungi [12].

The current occurrence of mycotoxins in barley could lead to the necessity of developing new strategies or improving those currently in place for more effective management of mycotoxins in the future. This fact is even more relevant when taking into account that the Brazilian regulation for DON in barley will be updated by 2019 [13] and therefore, the information on the occurrence of this toxin is still discussed in the country often.

The regulations have set maximum levels for mycotoxin contamination in grains, in order to avoid further accumulation of mycotoxins in processed food and to control mycotoxin of major concern in unprocessed cereals, such as brewing barley, with $1.250 \mu \mathrm{g} / \mathrm{kg}$ being the maximum permitted for DON and $100 \mu \mathrm{g} / \mathrm{kg}$ for ZEA. From January 2019, DON limits for brewing barley will be set at $1000 \mu \mathrm{g} / \mathrm{kg}$ [13]. Similarly, the limits for DON and ZEA fixed by the European Commission [14] are equal to $1.250 \mu \mathrm{g} / \mathrm{kg}$ and $100 \mu \mathrm{g} / \mathrm{kg}$ for unprocessed cereals.

For the reasons stated above, the aim of the present research was to characterize the Fusarium isolates and to assess DON and ZEA contamination in brewing barley grains. These findings provide 
new insights into the diversity of Fusarium species isolated from Brazilian barley and add information to the mycotoxin profile in a source (raw material) destined for the food industry.

\section{Results}

\subsection{Water Activity and Identification of Isolated Fungi}

Water activity levels ranged from 0.579 to 0.667 (mean: $0.622 \pm 0.02$ ) for all of the 64 brewing barley samples analyzed. Filamentous fungi were isolated from $96.8 \%$ of the samples, highlighting that Fusarium was the predominant genus (46\%), followed by Alternaria (28.8\%), Phoma (15\%), Epicocum (6.2\%), Penicillium (2\%), Aspergillus (1.1\%) and Rhyzopus (0.9\%). Species belonging to Fusarium genus were initially identified through the sequencing of the EF-1 $\alpha$ locus. Sequences were submitted to Blast (basic local alignment) tool on NCBI database (https:/ /blast.ncbi.nlm.nih.gov/Blast.cgi?PAGE_TYPE= BlastSearch).

The identification analysis was carried out with 48 Fusarium strains and sequencing analysis determined $56.26 \%$ of the Fusarium species isolated in this study, were within the Fusarium sambucinum species complex (FSAMSC), 31.25\% within the Fusarium tricinctum species complex (FTSC), 8.33\% within the Fusarium fujikuroi species complex (FFSC) and $2 \%$ within both, Fusarium incarnatum-equiseti (FIESC) and Fusarium oxysporum species complexes (FOSC) (Table 1).

Table 1. Frequency of the members of each Fusarium species complex isolated from brewing barley grains.

\begin{tabular}{cccc}
\hline Species Complex & Frequency $\%$ & Fusarium Species & \% Samples Contaminated \\
\hline \multirow{2}{*}{ FSAMSC } & \multirow{2}{*}{56.25} & F. graminearum & F. poae \\
& & F. meridionale & 17.2 \\
& \multirow{2}{*}{ FTSC } & F. avenaceum & 1.6 \\
\hline \multirow{2}{*}{ FFSC } & \multirow{2}{*}{ F.25 } & F. proliferatum & 23.4 \\
\hline FIESC & 2 & F. verticillioides & 3.1 \\
\hline FOSC & 2 & F. incarnatum-equiseti & 3.1 \\
\hline
\end{tabular}

* FSAMSC: F. sambucinum species complex, FTSC: F. tricinctum species complex, FFSC: F. fujikuroi species complex, FIESC: F. incarnatum-equiseti species complex, FOSC: F. oxyxporum species complex.

\subsection{Phylogenetic Study}

The phylogenetic study was conducted for the species complexes that have the potential to produce trichothecenes and for the closely related species complex F. tricinctum. The concatenated loci $E F-1 \alpha$ and $R P B 2$ were used to infer the phylogeny of the species isolated from barley. The data set consisted of 65 taxa, 1292 nucleotides with 452 parsimony-informative characters (PICs) (Figure 1). The analysis resulted in a one most parsimonious tree $(\mathrm{CI}=0.69 \mathrm{RI}=0.94)$. The majority of the isolates clustered within F. graminearum, F. poae and F. avenaceum species complexes with both posterior probability and bootstrap supports (Figure 1).

The method validation and recovery experiments are summarized in Table 2 and Table S2. The reported LODs were set at 5 and $10 \mu \mathrm{g} / \mathrm{kg}$ for DON and ZEA, respectively and LOQs $25 \mu \mathrm{g} / \mathrm{kg}$ for both toxins. The coefficients of correlation $\left(\mathrm{R}^{2}\right)$ of the calibration curve were 0.997 and 0.999 for DON and ZEA, respectively. Spiking was performed in triplicates at three levels in the barley matrix. In addition, the spiking experiments for the F. graminearum strains grown in culture media were carried out at two levels.

The method is suitable for the determination of mycotoxins in barley as the given LOQ's are lower than the maximum limit set by the Brazilian and EU regulations for the content of DON and ZEA. The parameter linearity, reproducibility, repeatability and recovery obtained were also shown to be adequate. 


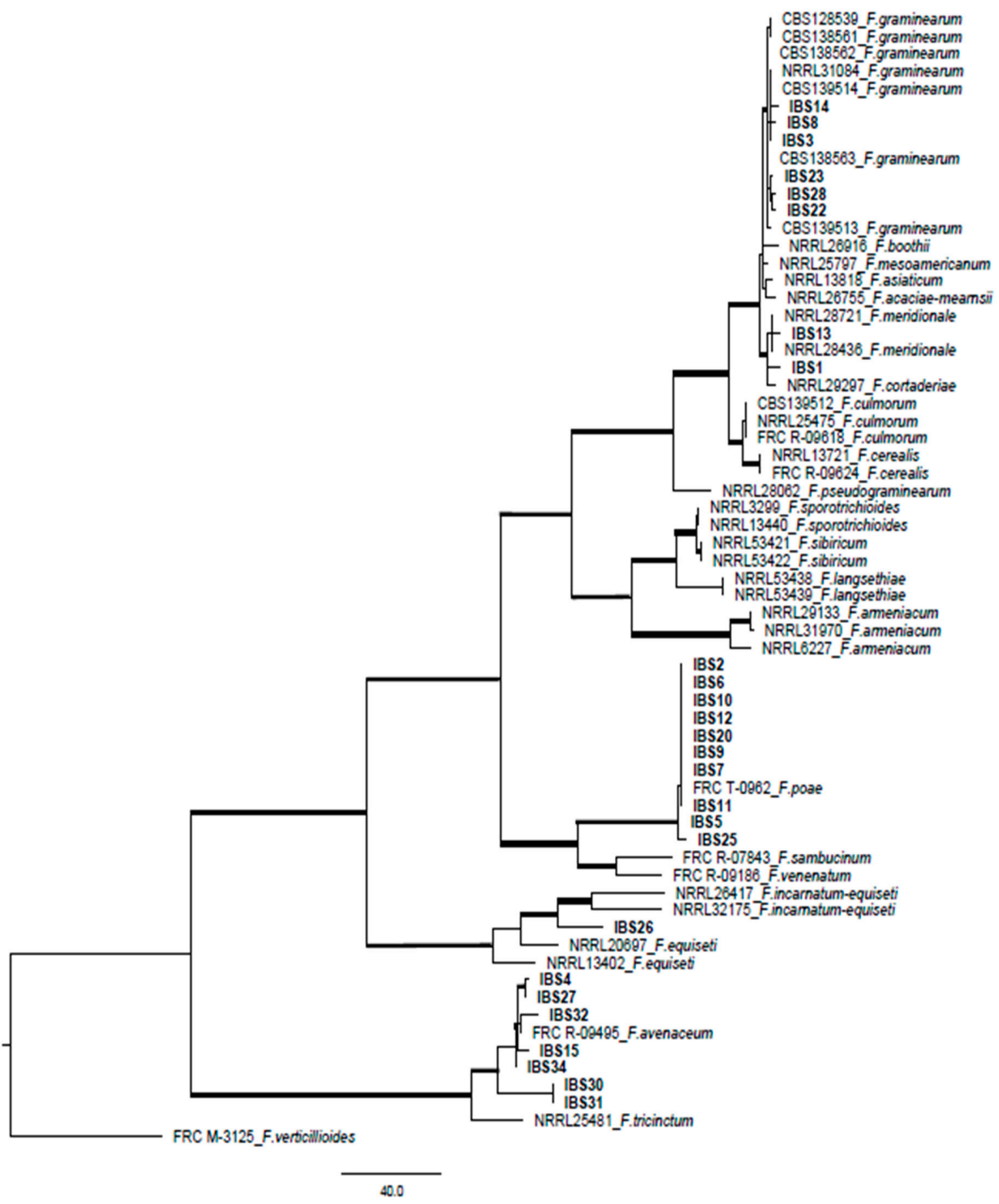

Figure 1. LC-MS/MS method performance.

\subsection{Mycotoxins Analysis}

The analysis carried out in the present research revealed the occurrence of the two mycotoxins most commonly found in barley. Grain samples that presented levels above the LOQ were considered positive. Mean calculations were performed using Microsoft ${ }^{\circledR}$ Excel 2007 only including positive samples. Deoxynivalenol showed the highest incidence $(90.6 \%)$ with levels ranging from 45.95 to $1155.21 \mu \mathrm{g} / \mathrm{kg}$. ZEA also had a high occurrence (87.5\%) with values ranging from 82.41 to $423.71 \mu \mathrm{g} / \mathrm{kg}$. Regarding the Brazilian regulation for DON, only one sample was above the established maximum levels $(1000 \mu \mathrm{g} / \mathrm{kg})$. Nevertheless, for ZEA, 55 samples $(86 \%)$ were above the regulation $(100 \mu \mathrm{g} / \mathrm{kg})$ (Table 2).

Additionally, the mycotoxin production from toxigenic potential F. graminearum strains was observed. The frequency of the DON strain producers was 80\% (12 strains) and only 20\% (3 strains) for ZEA. The levels ranged from 123.03 to $592.61 \mu \mathrm{g} / \mathrm{kg}$ and 33.64 to $140.58 \mu \mathrm{g} / \mathrm{kg}$, respectively. 
Table 2. DON and ZEA contamination in barley grains.

\begin{tabular}{|c|c|c|c|c|c|c|c|c|c|}
\hline & \multirow{2}{*}{$\begin{array}{l}\text { Number } \\
\text { Samples }\end{array}$} & \multicolumn{3}{|c|}{ Deoxynivalenol } & \multicolumn{5}{|c|}{ Zearalenone } \\
\hline & & $\begin{array}{c}\text { Positive } \\
\text { Samples } / \% \text { * }\end{array}$ & $\begin{array}{l}\text { Range of Positive } \\
\text { Samples ( } \mu \mathrm{g} / \mathrm{kg} \text { ) }\end{array}$ & $\begin{array}{c}\text { Mean } \pm \text { SD } \\
(\mu \mathrm{g} / \mathrm{kg})\end{array}$ & $\begin{array}{l}\text { Median } \\
(\mu \mathrm{g} / \mathrm{kg})\end{array}$ & $\begin{array}{c}\text { Positive } \\
\text { Samples } / \% \text { * }\end{array}$ & $\begin{array}{l}\text { Range of Positive } \\
\text { Samples ( } \mu \mathrm{g} / \mathrm{kg} \text { ) }\end{array}$ & $\begin{array}{c}\text { Mean } \pm \text { SD } \\
(\mu \mathrm{g} / \mathrm{kg})\end{array}$ & $\begin{array}{l}\text { Median } \\
(\mu \mathrm{g} / \mathrm{kg})\end{array}$ \\
\hline Barley grains & 64 & $58 / 90.6$ & $45.95-1155.21$ & $\begin{array}{c}147.65 \pm \\
167.16\end{array}$ & 98.68 & $56 / 87.5$ & $82.41-423.71$ & $\begin{array}{c}123.24 \pm \\
45.29\end{array}$ & 119.26 \\
\hline
\end{tabular}

* > LOQ of $25 \mu \mathrm{g} / \mathrm{kg}$. 


\section{Discussion}

This study has shown that the majority of the Fusarium species isolated from brewing barley grains belonged to the FSAMSC, whereas the main trichothecene producing species are clustered. Mycotoxins analysis demonstrated that most of the samples were contaminated with DON (90.6\%) and ZEA (87.5\%), highlighting the importance of this investigation.

Fusarium species are found in cereal grains, such as barley, wheat, maize and rice worldwide, where mycotoxins can be found in high concentrations [15-18]. This fact, may be worsened by weather conditions, such as high humidity and temperatures that tend to increase Fusarium infection in plants $[19,20]$. Humidity is an important environmental factor and it influences the water activity of the grains. This intrinsic factor is important for fungal growth and has considerable association with mycotoxin production [21].

Generally, Fusarium development as well as DON and ZEA production can be seen with higher levels of water activity (0.90) [22]. Nevertheless, the current research showed a low variation of the water activity that was observed among the 64 brewing barley samples, with mean value of $0.622 \pm 0.02$. In this case, both the germination of fungal spores and the growth of storage fungi are inhibited. However, the grain analyses were carried out after the cleaning and drying stages, explaining the levels found. For safe storage of grain, the grain moisture content must be compatible with the period of time the grain will be stored in order to avoid the fungi growth and therefore, the water activity should be less. To associate Fusarium mycotoxins found in this study it is necessary to assume that the DON and ZEA production could be correlated to the fungi presence and high water activity in the growing plant stages. This fact could be explained in our recent study with rice grains, where the levels of ZEA found are associated with the presence of Fusarium during pre-harvest, in grains freshly harvested with high levels of moisture content and water activity. After the food processing steps were completed in the industry, there was not any Fusarium growth in the grains, however, the ZEA levels remained in the parboiled rice (water activity: $0.64 \pm 0.02$ ), resisting the degradation [23].

The phylogenetic study showed that the majority of the strains clustered with F. graminearum, F. poae and F. avenaceum. Fusarium poae can produce high levels of nivalenol; therefore, further analyses should be done to investigate the degree of nivalenol contamination in Brazilian barley. Previous studies carried out by [24] in Russia and [25] in Italy have shown a high incidence of F. avenaceum in barley as well as other Fusarium species. [26] observed a high incidence of F. avenaceum, F. graminearum and F. culmorum in in Finnish barley grains between the years of 2005-14, with high levels of trichothecene contamination. The presence of F. avenaceum in barley may indicate the presence of enniatins, moniliformin and beauvericin in the samples. In Brazil, another study in barley has demonstrated that the majority of the isolates belonged to the F. graminearum lineage; however, mycotoxin analysis was not performed in that study [27]. To our knowledge, this is the first report of phylogenetic identification of the Fusarium species in Brazilian barley and the first correlation with DON and ZEA contamination.

With respect to DON contamination, the current study showed similarities with those found in a survey carried out in Spain with a mean level of $119.9 \mu \mathrm{g} / \mathrm{kg}$ [28]. In addition, the highest results were obtained by [25] reporting incidence and a maximum contamination level of $108.7 \mu \mathrm{g} / \mathrm{kg}$. Also, [29] in Italy, a study reported lower incidence and concentrations of DON with a maximum level of $35.5 \mu \mathrm{g} / \mathrm{kg}$; and [30] in Tunisia evaluated its presence with a maximum level of $6.1 \mu \mathrm{g} / \mathrm{kg}$. In the current study, only one sample presented a high level of DON (1155.21 $\mu \mathrm{g} / \mathrm{kg})$ and was above the established maximum level set by the Brazilian regulation. The samples showed mean values of $147.65 \mu \mathrm{g} / \mathrm{kg}$ and median values of $98.68 \mu \mathrm{g} / \mathrm{kg}$ that also demonstrated low levels.

In contrast, the ZEA contamination found in the present study were of significance, considering the maximum levels established by the Brazilian and international regulation, where $86 \%$ of the samples were above [13,31]. The samples showed mean values of $123.24 \mu \mathrm{g} / \mathrm{kg}$ and median values of $119.26 \mu \mathrm{g} / \mathrm{kg}$. In a study performed by [32] in the Czech Republic, a few samples were contaminated 
with ZEA with values ranging from 181.2 to $204.4 \mu \mathrm{g} / \mathrm{kg}$, which is quite similar to the results of our study. Furthermore, high levels $(\max 985.9 \mu \mathrm{g} / \mathrm{kg}$ ) of ZEA were found in another survey carried out in the Czech Republic with samples from the 2011 crop [33].

Two other studies were conducted in Brazil by the current author and can be compared to this study. The first one was from the 2014 crop and low levels of DON were found ranging from $200 \mu \mathrm{g} / \mathrm{kg}$ to $15.000 \mu \mathrm{g} / \mathrm{kg}$ [34]. The other one was from the $2015 \mathrm{crop}$ and higher levels were found for both toxins, DON and ZEA. The last study was considered an issue for the industry due to the levels exceeding the regulation levels established. The mean levels ranged from 1700 to $7500 \mu \mathrm{g} / \mathrm{kg}$ and from 300 to $630 \mu \mathrm{g} / \mathrm{kg}$ for DON and ZEA, respectively.

It is necessary to mention that not only the large-scale brewing industry is increasing but that the craft breweries in Brazil are expanding. These small brewing groups always look for the best sources and have the characteristic of "German beer purity law," meaning that just barley is used for beer production. For these reasons, barley needs to be of higher quality. On the other hand, the large-scale industry in Brazil uses other grains such as corn, rice and sorghum for beer production which are considered low quality grains [35]. Some studies were carried out and they showed contamination with fumonisin $B_{1}[36]$ that is commonly found in corn and its derivatives [37].

In the last years the stability of these metabolites has been studied. Deoxynivalenol showed to be a mycotoxin that persists through the process and demonstrated stability in some industry processes, such as cleaning, milling, brewing and extrusion [9]. Zearalenone has had some studies published about it which showed lower stability. However, its levels are high when they are found. A research conducted by [38] showed a considerable reduction of ZEA levels in the presence of Saccharomyces cerevisiae yeast. The main point is even if there is a significant reduction of these metabolites, sometimes they still offer a risk, especially when in beer, which is considered one of the most consumed beverages in the world.

Another aspect that should be taken into account is the masked toxins. ZEN-14-sulfate and DON-3-glucoside are most commonly observed in grains. They could be present in the matrix, however masked toxins are either bound to carbohydrates or proteins and, therefore, are not extractable with existing protocols aimed at the extraction of the toxin, or they are not detectable using established chromatography routines; hence their name "masked" mycotoxins [39]. Further studies are being planned to gain more knowledge on these metabolites in barley and also in beer.

The Fusarium mycotoxins found in barley grains and the toxigenic potential analysis of the F. graminearum strains isolated in this study reinforce the importance of these genera in this relevant commodity. Furthermore, the identification of F. poae, F. avenaceum and the genus Alternaria in barley samples highlights the importance of further research on other mycotoxins in barley and its by-products. Alternaria species were recovered from $28 \%$ of the barley samples. This may have important implications on other mycotoxins that may be found in high concentrations, such as tenuazonic acid. Further studies should be conducted in order to evaluate the co-occurrence of the mycotoxins produced by this genus $[25,40]$.

In this study, the toxigenic potential of the $F$. graminearum strains isolated in the brewing barley was evaluated and both toxins detected in the samples were produced by them. In total, $80 \%$ and $20 \%$ of the strains produced DON (mean: $297.02 \mu \mathrm{g} / \mathrm{kg}$ and median: $268.74 \mu \mathrm{g} / \mathrm{kg}$ ) and ZEA (mean: $79.7 \mu \mathrm{g} / \mathrm{kg}$ and median: $64.86 \mu \mathrm{g} / \mathrm{kg}$ ), respectively. The toxins levels found were lower when compared to that of a study performed by Wu et al. (2017), in which the strains exhibited a production of $1405.05 \mu \mathrm{g} / \mathrm{kg}$ for DON and $4118.31 \mu \mathrm{g} / \mathrm{kg}$ for ZEA. The parameter temperature is crucial for DON production and some studies showed a variation of the optimal value, that varies between 20 and $28{ }^{\circ} \mathrm{C}[19,20,41]$. On the other hand, temperature negatively affected ZEA production. The optimized condition for ZEA production was cultivation at $15^{\circ} \mathrm{C}$ [41]. The toxin combination can be related to several mycotoxigenic fungi that contaminate barley in the field. However, the mycotoxin occurrence in Brazilian barley suggests high prevalence of toxigenic $F$. graminearum and related species, which could explain the DON and ZEA levels in almost $85 \%$ of the samples. 


\section{Conclusions}

The DON and ZEA contamination in brewing barley grains were detected in $90.6 \%$ and $87.5 \%$ of the samples. The phylogenetic study showed that the majority of the strains clustered with F. graminearum, F. poae and F. avenaceum. Toxigenic species of F. graminareum isolates presented a higher percentage in the samples (31.25\%) and can explain the DON and ZEA contamination found in the barley samples. Taking into account the Brazilian regulation of ZEA levels in barley, $86 \%$ of the samples were significantly higher than the current maximum limit, while for DON, only one sample was above the established maximum levels. The Brazilian regulation for mycotoxins will be updated by 2019 and therefore, the new maximum limits are still under discussion, based on the analysis of the largest amount of data available of the occurrence of mycotoxins in the grains produced in Brazil. This monitoring data of the toxigenic Fusarium and its mycotoxins could lead to greater knowledge of the current situation of the barley contamination in the industry, which can assist Brazilian regulation and the programing of management strategies in order to avoid the toxic effects on human and animal health.

Fungal infection and the presence of mycotoxins in cereals is natural and the prevention of these occurrences is difficult even if good agricultural practices are maintained. The data provided in this study was important for the knowledge on Fusarium diversity and toxin contamination. Furthermore, the results highlight the importance of monitoring DON and ZEA contamination in barley grains during pre, post-harvest and in processed food, such as beer, mainly for the development of management strategies. Consequently, serious economic losses and health problems could potentially be avoided.

\section{Materials and Methods}

\subsection{Barley Samples}

A total of 64 brewing barley (BRS Brau variety) samples were obtained from the 2016 harvest, from the States of Paraná and Rio Grande do Sul, the largest barley-producing regions in Brazil. Samples were collected from bulk batches, after dirt removal and drying (up to $60{ }^{\circ} \mathrm{C}$ ) in the storage units. Sampling was performed using a grain auger from different points of the bulk batches, with a minimum final weight of $5 \mathrm{~kg}$. Each sample was homogenized, reduced into portions of $1.0 \mathrm{~kg}$ to be representative of the overall sample and further was milled for each analysis. Samples were packed in polyethylene bags and stored at $4{ }^{\circ} \mathrm{C}$ and different amounts were used for mycobiota and mycotoxin analyses.

\subsection{Water Activity}

To perform water activity (aw) analysis, $2 \mathrm{~g}$ of each barley sample were submitted to Aqua-Lab 4TE equipment Aqua-Lab 4TE, Decagon Devices (Sao Jose dos Campos, SP, Brazil). Samples were analyzed in triplicate according to the Association of Official Analytical Chemists-[42].

\subsection{Mycobiota and Identification of Fungi}

The dilution technique was used for fungal isolation, as described by [43]. To summarize briefly, twenty-five grams of each sample were added to $225 \mathrm{~mL}$ of $0.1 \%$ peptone dissolved in water in sterile conditions. The mixture was stirred on a rotary shaker for 2 min., dilutions of $10^{-1}, 10^{-2}, 10^{-3}$ and $10^{-4}$ were obtained, $0.1 \mathrm{~mL}$ aliquots of each dilution were spread on the PDA medium $[9,10]$ containing chloramphenicol $\left(100 \mathrm{mg} / \mathrm{L}\right.$ ) (in duplicate). These were incubated for 5 days, at $25^{\circ} \mathrm{C}$ in the dark. The results were expressed into colony forming units per gram (CFU/g) in the dilution $10^{-1}$, as the colonies were easily distinguished in this dilution factor. The isolates were identified morphologically according to Pitt and Hocking, (2009). 


\subsection{Identification of the Fusarium Species}

The strains were grown in yeast extract sucrose (YES) agar [44] for 3 days at $25{ }^{\circ} \mathrm{C}$. The DNA was extracted using DNeasy Plant Mini Kit (Qiagen, Hilden, Germany) according to the manufacturer's instructions.

The partial sequences of elongation factor $(E F-1 \alpha)$ and the second fragment of RPB2 (7CF/11AR) were selected in order to identify the Fusarium isolates. The amplification of the EF-1 $\alpha$ and $R P B 2$ loci were performed according to $[45,46]$. Amplicons were purified with ExoSAP-IT (Affymetrix, Santa Clara, CA, USA) and sent to the Centre of Human Genome Studies, University of Sao Paulo, Brazil for sequencing in ABI PRISM 3130 DNA Analyzer (Applied Biosystems, Foster City, CA, USA).

Sequences were aligned using the multiple alignment software ClustalX v. 1.83 plug-in in the software Geneious v. 5.3.6 (Biomatters, Auckland, New Zealand). The alignments were edited using the sequence alignment-editing program Geneious v. 1.83 and each polymorphism was re-examined by checking the chromatograms. The sequences generated in this study were deposited in the GenBank (Table 1 and Table S1).

\subsection{Phylogenetic Analysis}

Phylogenetic analysis was performed based on the EF-1 $\alpha$ and $R P B 2$ combined datasets using the PAUP 4.0b10 (Sinauer Associates, Sunderland, MA, USA) [47]. Phylogenies were obtained by using Unweighted Parsimony analysis and heuristic search option with 1000 random addition sequences and tree bisection reconnection branch swapping in PAUP 4.0b10 [48]. Gaps were treated as missing data. The Consistency Index (CI) and the Retention Index (RI) were calculated to indicate the amount of homoplasy present. Clade stability was assessed via bootstrap analysis in PAUP 4.0b10, using 1000 heuristic search replications with random sequence addition. The data sets were rooted with Fusarium sp. as it is considered a suitable out-group [49]. The reference sequences for the Fusarium species used in this study were obtained from NCBI (Table S1).

\subsection{Mycotoxin Analysis}

\subsubsection{Chemicals and Reagents}

Both standards (DON and ZEA) were purchased from Sigma Aldrich Chemicals (St. Louis, MO, USA). Stock solution standards were prepared in methanol at concentrations of $1 \mathrm{mg} / \mathrm{mL}$ for DON and ZEA. From the individual stock standard solutions, a standard mixture was prepared at the following concentrations: $0.025,0.0375,0.0625,0.125,0.375,0.500 \mu \mathrm{g} / \mathrm{mL}$. The standard mixture was prepared in methanol and stored at $-18{ }^{\circ} \mathrm{C}$. Methanol and acetonitrile (LC-MS/MS grade) were supplied by J.T Baker (Sao Paulo, SP, Brazil). Acetic acid was obtained from Biotec (Pinhais, PR, Brazil). High-purity Milli-Q water $(18.2 \mathrm{M} \Omega / \mathrm{cm})$ was obtained from the Millipore Synergy system (Billerica, MA, USA).

\subsubsection{DON and ZEA Extraction}

Mycotoxin extraction was carried out according to [50], with some minor modifications. Briefly, $2 \mathrm{~g}$ of brewing barley were ground and homogenized in $8 \mathrm{~mL}$ of acetonitrile:water (80:20 $\mathrm{v} / \mathrm{v})$ and shaken for $60 \mathrm{~min}$. The mixture was then centrifuged for $10 \mathrm{~min}$ at $3500 \mathrm{rpm}$. The supernatant was transferred to an amber vessel and dried using a heating block and a nitrogen stream. The dried extract was resuspended in $500 \mu \mathrm{L}$ of a mobile phase consisted of $70 \%$ of water:methanol:acetic acid (94:5:1, $v / v / v)$ and 30\% of water:methanol:acetic acid (2:97:1, $v / v / v)$. Finally, $5 \mu \mathrm{L}$ was injected in the LC-MS/MS system for analysis.

\subsection{Production of DON and ZEA by the Strains}

The isolates of F. graminearum were grown onto PDA (three agar plugs, $6 \mathrm{~mm}$ in diameter) and tested for DON and ZEA production. The culture media was incubated at $24{ }^{\circ} \mathrm{C}$ and $15{ }^{\circ} \mathrm{C}$ with a 
moisture content of $90 \%$ and $80 \%$ for 20 days for DON and ZEA, respectively [51,52]. The mycelium was transferred into an Erlenmeyer flask containing $30 \mathrm{~mL}$ of chloroform and shaken for $60 \mathrm{~min}$ for mycotoxin extraction, followed by filtration through anhydrous sodium sulfate $\left(\mathrm{Na}_{2} \mathrm{SO}_{4}\right)$. The extract was dried and re-suspended with $500 \mu \mathrm{L}$ of mobile phase. Finally, the extract was filtered with a syringe filter (nylon membrane $0.22 \mu \mathrm{M}$ ). The sample was quantified by liquid chromatography/mass spectrometry (LC-MS/MS) for DON/ZEA.

\subsection{Chromatography Conditions}

Detection and quantification were carried out using an LC-MS system from Thermo Scientific ${ }^{\circledR}$ (Bremen, Germany) composed of an ACCELA 600 quaternary pump, an ACCELAAS auto-sampler and a triple quadrupole mass spectrometer TSQ Quantum Max.

The chromatographic conditions were performed according to [53]. In short, the following instrumental settings were applied: the triple quadrupole mass spectrometer TSQ Quantum Max was operated at positive polarity and the ionization conditions were $208{ }^{\circ} \mathrm{C}$ for capillary temperature, $338{ }^{\circ} \mathrm{C}$ for vaporizer temperature, $4500 \mathrm{~V}$ for spray voltage and 60 arbitrary units for sheath gas pressure. For selectivity, the mass spectrometer was operated at MRM mode monitoring, three transitions per analyte, using a collision gas pressure of $1.7 \mathrm{mTorr}$ and collision energy (CE) ranging from 11 to $40 \mathrm{eV}$.

The mass spectrometric conditions were optimized by re-tuning different analytes by direct infusion of each analyte individually. The tube lens potential, collision energies and product ions were optimized and carefully chosen. The most abundant mass-to-charge ratio $(\mathrm{m} / \mathrm{z})$ was selected for each compound of interest. The mycotoxins exhibited precursor ions and product ions with reasonably high signal intensities in positive ESI mode (ESI+) and protonated molecules $[\mathrm{M}+\mathrm{H}]$ were found. Table S2 shows the retention times (tR), MRM transitions as well as the tube lens potential and collision energies optimized for each compound.

Separation was performed on a C8 Luna column, with a particle size of $3 \mu \mathrm{m}, 150 \times 2.0 \mathrm{~mm}$, length and diameter, respectively, Phenomenex (Torrance, CA, USA). In the mobile phase, solvent A (water:methanol:acetic acid, 94:5:1, v/v/v) and solvent B (water:methanol:acetic acid, 2:97:1, v/v/v) were used. The gradient program was applied at a flow rate of $0.2 \mathrm{~mL} / \mathrm{min}$ under the following conditions: $0-1 \mathrm{~min} 55 \% \mathrm{~B} ; 1-3 \mathrm{~min} 55-100 \% \mathrm{~B} ; 3.01-7 \mathrm{~min} 100 \% \mathrm{~B}$ and $7.01-12 \mathrm{~min} 55 \% \mathrm{~B}$. The total analytical run time was $7.5 \mathrm{~min}$ for the 2 toxins (Table 3 ).

Table 3. Retention time and mass spectrometric parameters used in the analysis of the mycotoxins.

\begin{tabular}{|c|c|c|c|c|c|}
\hline Mycotoxin & $\begin{array}{c}\text { Retention } \\
\text { Time (min) }\end{array}$ & $\begin{array}{l}\text { Precursor ion } \\
(\mathrm{m} / \mathrm{z})\end{array}$ & $\begin{array}{l}\text { Product ion } \\
(m / z) *\end{array}$ & CE (V) & TubeLens \\
\hline \multirow{3}{*}{ DON } & \multirow{3}{*}{2.19} & \multirow{3}{*}{$297[\mathrm{M}+\mathrm{H}]$} & $203 Q$ & 17 & 71 \\
\hline & & & $175 C$ & 18 & 71 \\
\hline & & & $91 \mathrm{C}$ & 39 & 71 \\
\hline \multirow{3}{*}{ ZEA } & \multirow{3}{*}{6.55} & \multirow{3}{*}{$319[\mathrm{M}+\mathrm{H}]$} & $283 Q$ & 11 & 79 \\
\hline & & & $187 \bar{C}$ & 25 & 79 \\
\hline & & & $185 C$ & 20 & 79 \\
\hline
\end{tabular}

${ }^{*} \mathrm{Q}$, Quantification transition C, Confirmation transition.

Method Validation

The methods for extraction of mycotoxins in brewing barley and in culture media with Fusarium growth were validated according to the Commission Regulation [54] guideline. To determine the limit of detection (LOD), limit of quantification (LOQ), recovery, repeatability and selectivity/specificity, samples with non-detectable levels of mycotoxins were submitted to spiking experiments. 
Considering linearity, a six-point calibration curve was constructed with the following concentrations of the mycotoxin standard mixture (DON and ZEN): 0.025, 0.0375, 0.0625, 0.125, $0.375,0.500 \mu \mathrm{g} / \mathrm{mL}$. The LOD and LOQ methods were determined by fortifying blank samples with different concentration levels and the experiments were repeated on three different days. The LOD was defined as the minimum concentration of an analyte in the spiked sample with a signal noise ratio equal to 3 and LOQ with a signal noise ratio equal to 10.

\subsection{Data Analysis}

Results regarding DON and ZEA in brewing barley samples and F. graminearum strains were reported as the mean \pm standard deviation and median, using Microsoft office Excel 2007.

Supplementary Materials: The following are available online at http:/ /www.mdpi.com/2072-6651/11/1/31/s1, Table S1: Fusarium species references used in this study for phylogenetic analysis, Table S2: Characteristics of the method performance for extraction of deoxynivalenol and zearalenone in barley grains and culture media.

Author Contributions: The authors' responsibilities were as follows-K.C.P. and L.O.R. designed the research; K.C.P., L.D.C.F. and L.C.-Q.: conducted the research; G.D.S.: guided and performed the statistical analysis; B.C.: Oversight and leadership responsibility for the research activity planning and execution, K.C.P. wrote the manuscript and hold primary responsibility for the final content; and all authors: read and approved the final manuscript.

Funding: The authors thank to the Research support foundation of the state of Sao Paulo (FAPESP/Project 2016/01798-4) for financial support.

Conflicts of Interest: The authors declare no conflict of interest.

\section{References}

1. Desjardins, A.E. Fusarium Mycotoxins: Chemistry, Genetics and Biology. Plant Pathol. 2007, 56, 337. [CrossRef]

2. Ma, L.-J.; Geiser, D.M.; Proctor, R.H.; Rooney, A.P.; O’Donnell, K.; Trail, F.; Gardiner, D.M.; Manners, J.M.; Kazan, K. Fusarium pathogenomics. Annu. Rev. Microbiol. 2013, 67, 399-416. [CrossRef]

3. FAO. FAO Statistical Yearbook 2013: World Food and Agriculture; FAO: Rome, Italy, 2013; ISBN 9789251073964.

4. WHO. International Programme on Chemical Safety (IPCS): Environmental Health Criteria 105 Selected Mycotoxins: Ochratoxins, Trichothecenes, Ergot. Trichothecenes; World Health Organization: Geneva, Switzerland, 1990; pp. 71-164.

5. Pestka, J.J. Deoxynivalenol: Mechanisms of action, human exposure, and toxicological relevance. Arch. Toxicol. 2010, 84, 663-679. [CrossRef] [PubMed]

6. Zinedine, A.; Soriano, J.M.; Moltó, J.C.; Mañes, J. Review on the toxicity, occurrence, metabolism, detoxification, regulations and intake of zearalenone: An oestrogenic mycotoxin. Food Chem. Toxicol. 2007, 45, 1-18. [CrossRef] [PubMed]

7. International Agency for Research on Cancer. IARC Monographs on the Evaluation of Carcinogenic Risks to Humans; International Agency for Research on Cancer: Lyon CEDEX, France, 2002; Volume 96. [CrossRef]

8. Pascari, X.; Ramos, A.J.; Marín, S.; Sanchís, V. Mycotoxins and beer. Impact of beer production process on mycotoxin contamination. A review. Food Res. Int. 2018, 103, 121-129. [CrossRef]

9. Bullerman, L.B.; Bianchini, A. Stability of mycotoxins during food processing. Int. J. Food Microbiol. 2007, 119, 140-146. [CrossRef] [PubMed]

10. Piacentini, K.C.; Savi, G.D.; Olivo, G.; Scussel, V.M. Quality and occurrence of deoxynivalenol and fumonisins in craft beer. Food Control 2015, 50, 925-929. [CrossRef]

11. Piacentini, K.C.; Rocha, L.O.; Savi, G.D.; Carnielli-Queiroz, L.; Almeida, F.G.; Minella, E.; Corrêa, B. Occurrence of deoxynivalenol and zearalenone in brewing barley grains from Brazil. Mycotoxin Res. 2018. [CrossRef]

12. Wegulo, S.N.; Baenziger, P.S.; Hernandez Nopsa, J.; Bockus, W.W.; Hallen-Adams, H. Management of Fusarium head blight of wheat and barley. Crop Prot. 2015, 73, 100-107. [CrossRef] 
13. Brasil Limites Máximos Tolerados (LMT) Para Micotoxinas; Agência Nacional Vigilância Sanitária: ANVISA, Brazil, 2017.

14. European Commission. Commission Regulation (EC) No 1881/2006 of 19 December 2006 setting maximum levels for certain contaminants in foodstuffs. Off. J. Eur. Union 2006, L364, 5-24.

15. Karlsson, I.; Friberg, H.; Kolseth, A.K.; Steinberg, C.; Persson, P. Agricultural factors affecting Fusarium communities in wheat kernels. Int. J. Food Microbiol. 2017, 252, 53-60. [CrossRef] [PubMed]

16. Hofer, K.; Geißinger, C.; König, C.; Gastl, M.; Hückelhoven, R.; Heß, M.; Coleman, A.D. Influence of Fusarium isolates on the expression of barley genes related to plant defense and malting quality. J. Cereal Sci. 2016, 69, 17-24. [CrossRef]

17. Silva, J.J.; Viaro, H.P.; Ferranti, L.S.; Oliveira, A.L.M.; Ferreira, J.M.; Ruas, C.F.; Ono, E.Y.S.; Fungaro, M.H.P. Genetic structure of Fusarium verticillioides populations and occurrence of fumonisins in maize grown in Southern Brazil. Crop Prot. 2017, 99, 160-167. [CrossRef]

18. Choi, S.; Jun, H.; Bang, J.; Chung, S.H.; Kim, Y.; Kim, B.S.; Kim, H.; Beuchat, L.R.; Ryu, J.H. Behaviour of Aspergillus flavus and Fusarium graminearum on rice as affected by degree of milling, temperature, and relative humidity during storage. Food Microbiol. 2015, 46, 307-313. [CrossRef] [PubMed]

19. Garcia, D.; Barros, G.; Chulze, S.; Ramos, A.J.; Sanchis, V.; Marín, S. Impact of cycling temperatures on Fusarium verticillioides and Fusarium graminearum growth and mycotoxins production in soybean. J. Sci. Food Agric. 2012, 92, 2952-2959. [CrossRef] [PubMed]

20. Llorens, A.; Mateo, R.; Hinojo, M.J.; Valle-Algarra, F.M.; Jiménez, M. Influence of environmental factors on the biosynthesis of type B trichothecenes by isolates of Fusarium spp. from Spanish crops. Int. J. Food Microbiol. 2004, 94, 43-54. [CrossRef] [PubMed]

21. Fleurat-Lessard, F. Integrated management of the risks of stored grain spoilage by seedborne fungi and contamination by storage mould mycotoxins-An update. J. Stored Prod. Res. 2017, 71, 22-40. [CrossRef]

22. Pitt, J.I.; Hocking, A.D. Fungi and Food Spoilage; Springer: Berlin/Heidelberg, Germany, 2009; ISBN 9780387922065.

23. Savi, G.D.; Piacentini, K.C.; Rocha, L.O.; Carnielli-Queiroz, L.; Furtado, B.G.; Scussel, R.; Zanoni, E.T.; Machado-de-Ávila, R.A.; Corrêa, B.; Angioletto, E. Incidence of toxigenic fungi and zearalenone in rice grains from Brazil. Int. J. Food Microbiol. 2018, 270. [CrossRef]

24. Stakheev, A.A.; Khairulina, D.R.; Zavriev, S.K. Four-locus phylogeny of Fusarium avenaceum and related species and their species-specific identification based on partial phosphate permease gene sequences. Int. J. Food Microbiol. 2016, 225, 27-37. [CrossRef]

25. Beccari, G.; Caproni, L.; Tini, F.; Uhlig, S.; Covarelli, L. Presence of Fusarium species and other toxigenic fungi in malting barley and multi-mycotoxin analysis by liquid chromatography-high-resolution mass spectrometry. J. Agric. Food Chem. 2016, 64, 4390-4399. [CrossRef]

26. Hietaniemi, V.; Rämö, S.; Yli-Mattila, T.; Jestoi, M.; Peltonen, S.; Kartio, M.; Sieviläinen, E.; Koivisto, T.; Parikka, P. Updated survey of Fusarium species and toxins in Finnish cereal grains. Food Addit. Contam. Part A Chem. Anal. Control. Expo. Risk Assess. 2016, 33, 831-848. [CrossRef] [PubMed]

27. Astolfi, P.; dos Santos, J.; Schneider, L.; Gomes, L.B.; Silva, C.N.; Tessmann, D.J.; Del Ponte, E.M. Molecular survey of trichothecene genotypes of Fusarium graminearum species complex from barley in Southern Brazil. Int. J. Food Microbiol. 2011, 148, 197-201. [CrossRef] [PubMed]

28. Ibáñez-Vea, M.; González-Peñas, E.; Lizarraga, E.; López de Cerain, A. Co-occurrence of mycotoxins in Spanish barley: A statistical overview. Food Control 2012, 28, 295-298. [CrossRef]

29. Juan, C.; Ritieni, A.; Mañes, J. Occurrence of Fusarium mycotoxins in Italian cereal and cereal products from organic farming. Food Chem. 2013, 141, 1747-1755. [CrossRef] [PubMed]

30. Juan, C.; Berrada, H.; Maes, J.; Oueslati, S. Multi-mycotoxin determination in barley and derived products from Tunisia and estimation of their dietary intake. Food Chem. Toxicol. 2017, 103, 148-156. [CrossRef] [PubMed]

31. 401/2006/EC Commision Regulation (EC) No 401/2006 of 23 February 2006 laying down the methods of sampling and analysis for the official control of the levels of mycotoxins in foodstuffs. Off. J. Eur. Union 2006, L70, 12-34. 
32. Bolechová, M.; Benešová, K.; Běláková, S.; Čáslavský, J.; Pospíchalová, M.; Mikulíková, R. Determination of seventeen mycotoxins in barley and malt in the Czech Republic. Food Control 2015, 47, 108-113. [CrossRef]

33. Běláková, S.; Benešová, K.; Čáslavský, J.; Svoboda, Z.; Mikulíková, R. The occurrence of the selected fusarium mycotoxins in czech malting barley. Food Control 2014, 37, 93-98. [CrossRef]

34. Piacentini, K.C.; Savi, G.D.; Pereira, M.E.V.; Scussel, V.M. Fungi and the natural occurrence of deoxynivalenol and fumonisins in malting barley (Hordeum vulgare L.). Food Chem. 2015, 187. [CrossRef]

35. Poreda, A.; Czarnik, A.; Zdaniewicz, M.; Jakubowski, M.; Antkiewicz, P. Corn grist adjunct-Application and influence on the brewing process and beer quality. J. Inst. Brew. 2014, 120, 77-81. [CrossRef]

36. Piacentini, K.C.; Rocha, L.O.; Fontes, L.C.; Carnielli, L.; Reis, T.A.; Corrêa, B. Mycotoxin analysis of industrial beers from Brazil: The influence of fumonisin B1and deoxynivalenol in beer quality. Food Chem. 2017, 218. [CrossRef] [PubMed]

37. Oliveira, M.S.; Rocha, A.; Sulyok, M.; Krska, R.; Mallmann, C.A. Natural mycotoxin contamination of maize (Zea mays L.) in the South region of Brazil. Food Control 2016, 1-6. [CrossRef]

38. Zhang, H.; Dong, M.; Yang, Q.; Apaliya, M.T.; Li, J.; Zhang, X. Biodegradation of zearalenone by Saccharomyces cerevisiae: Possible involvement of ZEN responsive proteins of the yeast. J. Proteom. 2016, 143, 416-423. [CrossRef] [PubMed]

39. Gareis, M.; Bauer, J.; Thiem, J.; Plank, G.; Grabley, S.; Gedek, B. Cleavage of Zearalenone-Glycoside, a "Masked" Mycotoxin, during Digestion in Swine. J. Vet. Med. Ser. B 1990, 37, 236-240. [CrossRef]

40. Efsa Scientific Opinion on the risks for animal and public health related to the presence of Alternaria toxins in feed and food. EFSA J. 2011, 9, 97. [CrossRef]

41. Wu, L.; Qiu, L.; Zhang, H.; Sun, J.; Hu, X.; Wang, B. Optimization for the production of deoxynivalenol and zearalenone by Fusarium graminearum using response surface methodology. Toxins (Basel) 2017, 9. [CrossRef] [PubMed]

42. AOAC. Official Methods of Analysis of AOAC International; AOAC: Rockville, MD, USA, 2005; ISBN 0935584544.

43. Silva, N.D.; Junqueira, V.C.; Silveira, N.F.; Taniwaki, M.; Santos, R.F.; Gomes, R.A. Manual de Métodos de Análise Microbiológica de Alimentos e Água, 4th ed.; Português: Sao Paulo, Barzil, 2010.

44. Degola, F.; Berni, E.; Dall'Asta, C.; Spotti, E.; Marchelli, R.; Ferrero, I.; Restivo, F.M. A multiplex RT-PCR approach to detect aflatoxigenic strains of Aspergillus flavus. J. Appl. Microbiol. 2007, 203, 409-427. [CrossRef] [PubMed]

45. Geiser, D.M.; Jiménez-Gasco, M.D.M.; Kang, S.; Makalowska, I.; Veeraraghavan, N.; Ward, T.J.; Zhang, N.; Kuldau, G.A.; O'Donnell, K. FUSARIUM-ID v. 1.0: A DNA sequence database for identifying Fusarium. Eur. J. Plant Pathol. 2004, 110, 473-479. [CrossRef]

46. O'Donnell, K.; Ward, T.J.; Geiser, D.M.; Kistler, H.C.; Aoki, T. Genealogical concordance between the mating type locus and seven other nuclear genes supports formal recognition of nine phylogenetically distinct species within the Fusarium graminearum clade. Fungal Genet. Biol. 2004, 41, 600-623. [CrossRef]

47. Swofford, D.L. PAUP* phylogenetic analysis using parsimony (*and other methods). Version 4.0b10. Sinauer Assoc. 2002. [CrossRef]

48. Swofford, D.L. Phylogenetic Analysis Using Parsimony. Options 2002, 42, 294-307. [CrossRef]

49. O’Donnell, K.; Rooney, A.P.; Proctor, R.H.; Brown, D.W.; McCormick, S.P.; Ward, T.J.; Frandsen, R.J.N.; Lysøe, E.; Rehner, S.A.; Aoki, T.; et al. Phylogenetic analyses of RPB1 and RPB2 support a middle Cretaceous origin for a clade comprising all agriculturally and medically important fusaria. Fungal Genet. Biol. 2013, 52, 20-31. [CrossRef] [PubMed]

50. Al-Taher, F.; Cappozzo, J.; Zweigenbaum, J.; Lee, H.J.; Jackson, L.; Ryu, D. Detection and quantitation of mycotoxins in infant cereals in the U.S. market by LC-MS/MS using a stable isotope dilution assay. Food Control 2017, 72, 27-35. [CrossRef]

51. Savi, G.D.; Vitorino, V.; Bortoluzzi, A.J.; Scussel, V.M. Effect of zinc compounds on Fusarium verticillioides growth, hyphae alterations, conidia, and fumonisin production. J. Sci. Food Agric. 2013, 93, 3395-3402. [CrossRef]

52. Savi, G.D.; Bortoluzzi, A.J.; Scussel, V.M. Antifungal properties of Zinc-compounds against toxigenic fungi and mycotoxin. Int. J. Food Sci. Technol. 2013, 48, 1834-1840. [CrossRef] 
53. Njumbe Ediage, E.; Van Poucke, C.; De Saeger, S. A multi-analyte LC-MS/MS method for the analysis of 23 mycotoxins in different sorghum varieties: The forgotten sample matrix. Food Chem. 2015, 177, 397-404. [CrossRef] [PubMed]

54. EC Commission regulation (EC) 401/2006 of 23 february 2006 laying down the methods of sampling and analysis for the official control of the levels of mycotoxins in foodstuffs. Off. J. Eur. Communities 2000, L269, $1-15$.

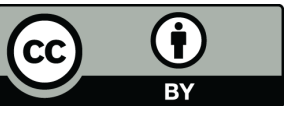

(C) 2019 by the authors. Licensee MDPI, Basel, Switzerland. This article is an open access article distributed under the terms and conditions of the Creative Commons Attribution (CC BY) license (http:/ / creativecommons.org/licenses/by/4.0/). 